\title{
Proposal of a New Vietnam Production Model, NVPM: A New Integrated Production System of Japan and Vietnam
}

\author{
Shogo Miyashita ${ }^{1}$, Kakuro Amasaka ${ }^{2}$ \\ ${ }^{1}$ (Graduate School of Science and Engineering,Aoyama Gakuin University, Japan) \\ ${ }^{2}$ (College of Science and Engineering, Aoyama Gakuin University, Japan)
}

\begin{abstract}
Automakers in Vietnam are currently expanding production with the intent of becoming a global industry. At the same time, these manufacturers need a production strategy to beat out the global quality competition and overcome associated new challenges, including the management of quality, production, and personnel and strategic collaboration with overseas automakers. Thus, seeing the need to improve the quality of Vietnamese automobile manufacturing in the future, the authors have constructed the "New Vietnam Production Model, NVPM". This model integrates the Total Production System (TPS), the leading Japanese production system, and the current Vietnamese production system from a new perspective. Specifically, the authors' research examines (i) the successful "Advanced TPS," which is an advanced model of the TPS, and (ii) the Traditional Vietnamese Production System (VPS-T), which is currently established in Vietnam, as well as the localized Vietnamese Production System (VPS-L). Based on the findings, the authors constructed the NVPM, which intelligently integrates Advanced TPS and VPS-T\&L.
\end{abstract}

Keywords: Globalization, TPS, Advanced TPS, New Vietnam Production Model (NVPM)

\section{Introduction}

In addition to increasing production volumes with the aim of achieving globalization, the Vietnamese automobile industry is now required to implement production strategies that will enable survival in the "global quality competition." This will involve overcoming new challenges such as quality management, production management, human resources management, and strategic link-ups with overseas automobile manufacturers ([10]). Thus, seeing the need to improve the quality of Vietnamese automobile manufacturing in the future, the authors have constructed a "New Vietnam Production Model" (NVPM). Above all, the production systems employed by the automobile industry are lagging behind compared to advanced companies in terms of people's awareness, standardization, and efficiency improvements. Thus, the authors create a new Vietnamese production model focusing on the automobile industry.

In the past, the authors have proposed a "New Global Partnering Production Model" and conducted research to investigate its effectiveness ([11]). They have also proposed a "New Turkish Production Model" and a "New Malaysia Production Model" based on Advanced TPS, and the required results have been attained with these models ([15]). Using these new production models as a benchmark, the authors have constructed a "New Vietnam Production Model" (NVPM) to enable Vietnamese production to keep pace with advanced countries.

\section{Research background and field survey}

Japanese companies are looking to countries such as China, Thailand, Vietnam, and India as viable prospects for overseas bases. Currently, under the national "industrialization" policy Vietnam aims to enter the ranks of industrial nations by 2020. Thus, the authors are focusing on the automobile sector of the general assembly industry.

Vietnam now has an urgent need for a new production system to enhance the country's competitive strength. Looking at the industry composition ratio of the country's actual domestic general production, the proportion covered by the manufacturing industry was $41.0 \%$ in 2005 and further growth is expected in this industry area.

Traditional Vietnamese Production System (VPS-T) is often performed manually assembling and inspection.Recent years, Vietnams companies depend on the import from the foreign countries for the high facilities, but the simple work employs a person. Currently, there are many companies introducing production systems, such as Japan which is a developed country.

\section{Progress Of Japanese Production}

The TPS lies at the core of manufacturing in Japan ([12],[13],[14]); in recent years, it has progressed as a core technology of "New JIT", new principle of next-generation production management technology ([1],[4]). 


\subsection{Total Production System,TPS}

Its main focus is to enable the strengthening and enhancement of the policies of "customer-first, emphasis on employees and process management" through the incorporation of the four elements (a) to (d) shown in Fig.1. As the diagram shows, the fundamental principle of TPS is to realize the strengthening and enhancement of customer-first, emphasis on employees and process management policies through the incorporation of the four key elements: (a) production by information, (b) production by workplace configuration, (c) production by technology, and (d) production by management.

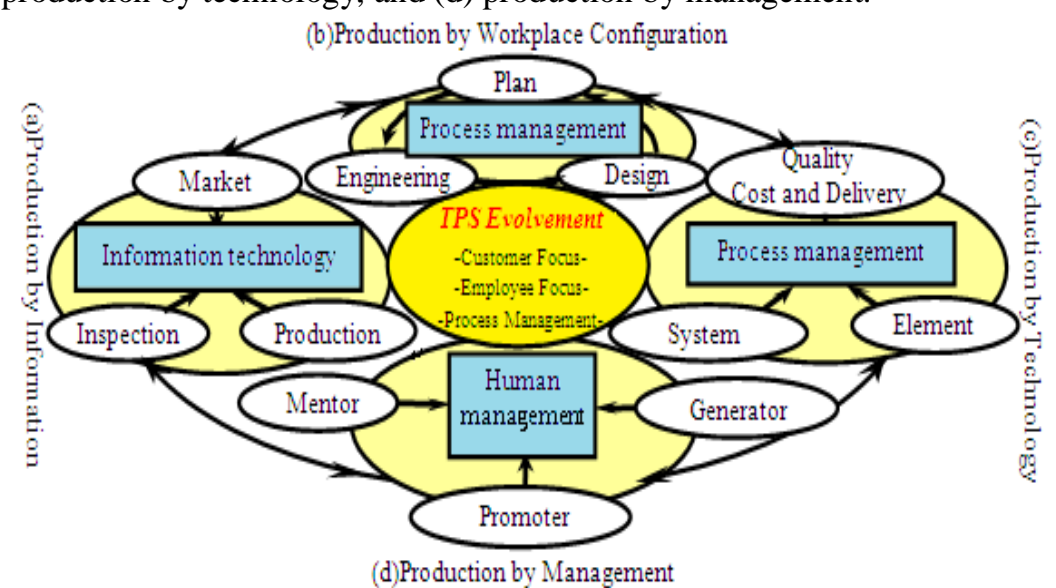

Fig.1: Total Production System

The first element that must be deployed is production by information (a). This means innovation of the production management system that gives priority to quality information available both inside and outside of the company. This requires reformation of the production philosophy in order to break free from the conventional practices. Production by workplace configuration (b) entails the creation of a rational production process and reform of the workplace configuration in accordance with this. Production by technology (c) involves reinforcement of production technology through product quality, cost and delivery (QCD) research activities that utilize the latest production technology. Finally, production by management (d) requires understanding the importance of human management and creating a highly creative and active workplace which utilizes and nurtures individuals' innate abilities.

\subsection{Advanced TPS}

The authors ([2],[5]) proposed Advanced TPS, an evolved model of TPS for the strategic deployment of global production as shown in Fig.2, and have verified its effectiveness at Toyota.

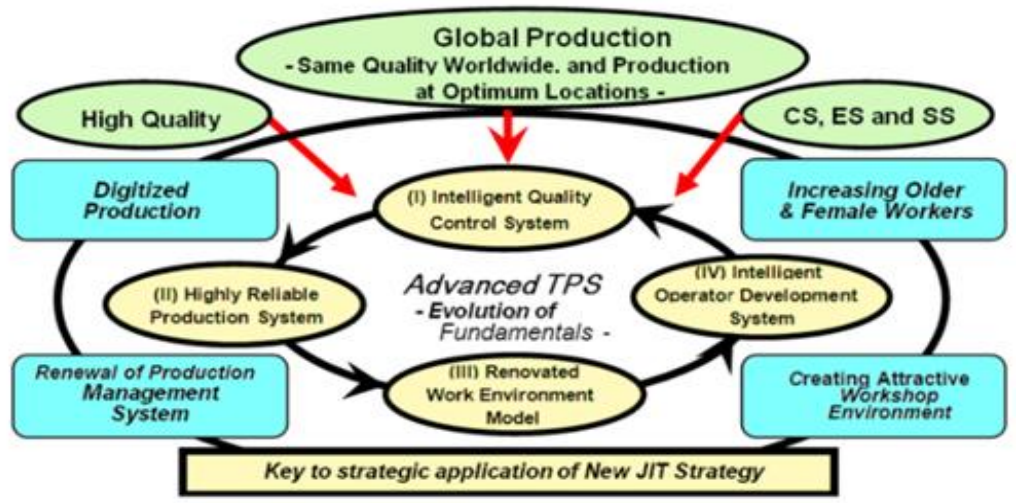

Fig.2: Advanced TPS

The objective of this model is the systemization of a new, next-generation Japanese production management system and this involves the high-cyclization of the production process for realizing the simultaneous achievement of QCD requirements. The mission of Advanced TPS is to contribute to worldwide uniform quality and simultaneous launch (production at optimal locations) as a strategic deployment of global production and to realize Customer Satisfaction (CS), Employee Satisfaction (ES), and Social Satisfaction (SS) through high quality assurance manufacturing.

In order to make this model into a reality it will be necessary to adapt it to handle digitalized production and reform it to realize an advanced production management system. Furthermore, other 
prerequisites for realizing this include the need to create an attractive working environment that can accommodate the increasing number of older and female workers at the production sites and to cultivate intelligent production operators. These measures need to be organically combined and spiraled up in order to make the simultaneous achievement of QCD possible.

One of the technical elements necessary for fulfilling these requirements is the reinforcement of maintenance and improvement of process capabilities by establishing an intelligent quality control system. Second, a highly reliable production system needs to be established for high quality assurance. Third, reform is needed for the creation of a next-generation working environment that enhances intelligent productivity. Fourth, intelligent production operators need to be cultivated who are capable of handling the advanced production system and an intelligent production operating system needs to also be established. Worldwide uniform quality and simultaneous launch (production at optimal locations) are being achieved through strategic management of these elements.

\subsection{Application}

The authors indicates some strategic development examples of how New Japan Global Production Model.Global production must be deployed in order to establish the kind of manufacturing that is required to gain the trust of customers around the world by achieving a high level of quality assurance and efficiency and shortening lead times to reinforce the simultaneous achievement of QCD requirements ([3]). The vital key to achieving this is the introduction of a production system that incorporates production machinery automated with robots, skilled and experienced workers (production operators) to operate the machinery and, further, production information to organically combine them.

Thus, having recognized the need for a new production system suitable for global production, the authors havecreateda NJ-GPM shown in Fig. 3 to realize the strategic deployment of the Advanced TPS.

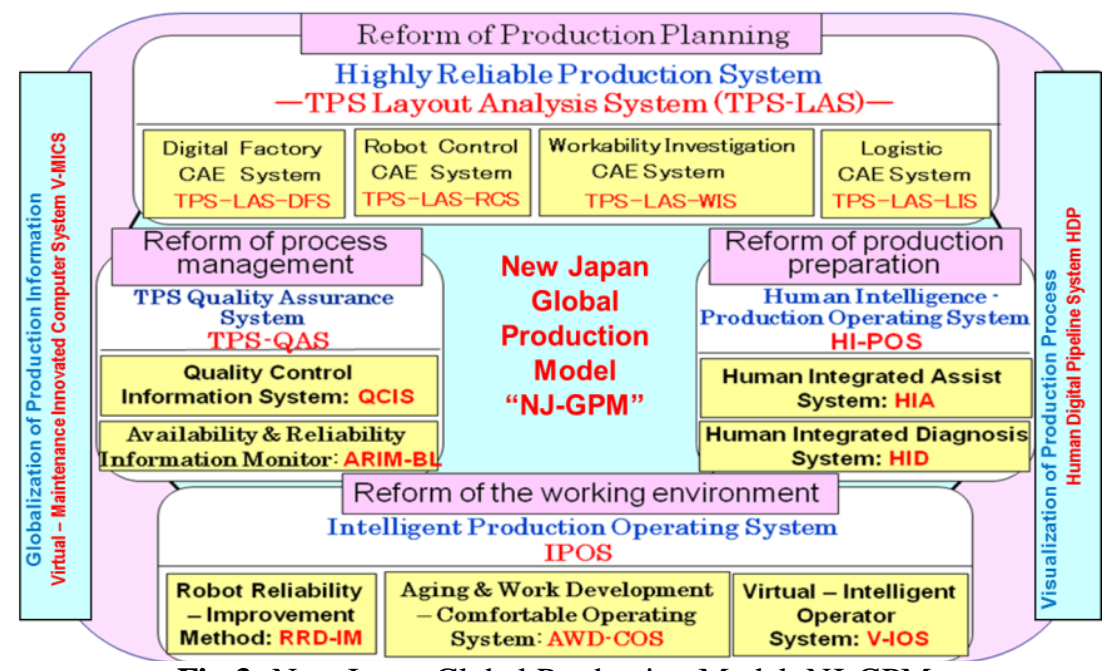

Fig.3: New Japan Global Production Model, NJ-GPM

The purposeof this model is to eradicate ambiguities at each stage of the production process from production planning and preparation through production itself and process management, and between the processes in order to achieve a highly reliable production system for global production which will improve the reliability ofmanufacturingthrough the clarification and complete coordination of these processes.

More specifically, the model is intended to (i) employ numeric simulation (Computer Aided Engineering, CAE) and computer graphics (CG) right from the production planning stage to resolve technical issues before they occur, (ii) reinforce production operators' high-techmachine operating skills and manufacturing capabilities, and (iii)visualize the aboveusingInformation Technology (IT) in order to reform production information systems to create a global network of production sites around the world.

The six core technologies that constitute this model and their characteristics are described below.

(1) Reform of production planning: TPS-LAS ([7]) is aproduction optimization system intended to realize a highly reliable production system by optimizing the layout of both the production site as a whole and each production process with regard to production lines (logistics and transportation), robots (positioning), and production operators (allocation and workability) through the use of numeric simulation. TPS-LAS is made up of four sub-systems: Digital Factory CAE System (LAS-DFS), Robot Control CAE System (LAS-RCS), Workability Investigation CAE System (LAS-WIS), and Logistic Investigation CAE System (LAS-LIS). 
(2) Reform of production preparation:HI-POS ([8]) is an intelligent operator development system intended to enable the establishment of a new people-oriented production system whereby training is conducted to ensure that operators develop the required skills to a uniform level, and diagnosis is then carried out to ensure that the right people are assigned to the right jobs. HI-POS is made up of two sub-systems: Human Intelligence Diagnosis System (HID) and Human Integrated Assist System (HIA).

(3) Reform of the working environment: Intelligent Production Operating System (IPOS) is intended to lead to a fundamental reform of the work involved inproduction operations by raising the technical skills level of production operators and further improving the reliability of their skills for operating advanced production equipment within an optimized working environment. IPOS is made up of three sub-systems: Virtual Intelligent Operator System(V-IOS), Aging \& Work Development - Comfortable Operating System (AWDCOS), and Robot Reliability Design-Improvement Method (RRD-IM).

(4) Reform of process management: TPS-QAS is an integrated quality control system intended to ensure that quality is built into production processes through scientific process management that employs statistical science to secure process capability $(\mathrm{Cp})$ and machine capability $(\mathrm{Cm})([9])$. TPS-QAS is made up of two sub-systems: Quality Control Information System (QCIS), and Availability \& Reliability Information Monitor System (ARIM).

(5) Visualization of production processes: HDP ensures that top priority is given to customers through manufacturing with a high level of quality assurance. This involves the visualization of intelligent production information throughout product design, production planning and preparation, and production processes, therebyfacilitating the complete coordination of these processes. This system enables the high-cyclization of business processes within manufacturing.

(6) Globalization of production information: V-MICS ([6])is a global network system for the systemization of production management technology necessary to realize a highly reliable production system, which is required to achieve worldwide uniform quality and production at optimal locations.

The created NJ-GPM is fundamental to the strategic deployment of Advanced TPS. Through the operation of a dual system involving both V-MICS and HDP, this new model integrates the core technologies from production planning and preparation through working environments and process management. In the next section, the author verifies the effectiveness of this research through some examples illustrating the deployment of NJ-GPM.

\section{Proposal of a new Vietnam production model,NVPM}

Having investigated the current situation of the automobile industry in Vietnam, the authors have proposed a concept model for a"New Vietnam Production Model, NVPM".

\subsection{NVPM Concept Model}

This model integrates the Traditional Vietnamese Production System (VPS-T) and the Localized Vietnamese Production System (VPS-L), based on the core technology of the Total Production System (TPS), the leading Japanese production system, and the "Advanced TPS," which is an advanced model of the Total Production System that enables global production.

In proposing this concept model, the authors conducted field surveys of automobile suppliers and assembly companies that are implementing and developing VPS-T and VPS-L. Similarly, the authors also conducted field surveys of several companies that are implementing and developing TPS and Advanced TPS, such as Toyota Vietnam. The surveys focused mainly on aspects such as 4ME, management perspectives, employee awareness, the Vietnamese national character, quality management at plants, and human resources management.

As a result, the authors aimed to create a NVPM as "hybrid" model (TPS + Advanced TPS + VPS-T + VPS-L) shown in Fig.4.

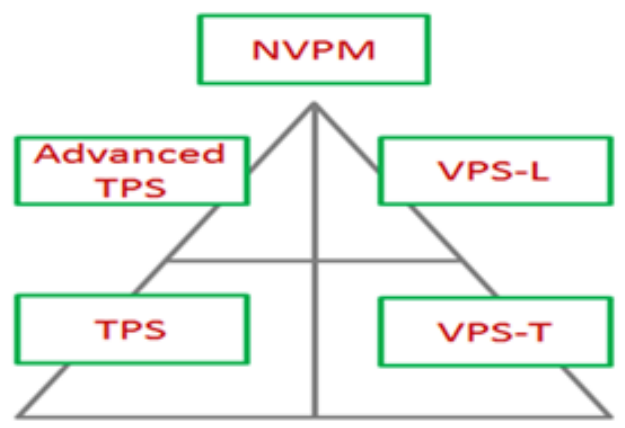

Fig.4: Concept Model of NVPM 
4.2Field Survey

The authors made appointments with Japanese companies that have bases in Vietnam, and conducted field surveys to determine the actual situation there. The figures below show Japanese companies that the authors visited in Vietnam. While working alongside the workers in Vietnam, the authors noticed differences from Japan. In particular, they noticed that workers tend to do the jobs that they are given exactly as instructed, and prefer simple tasks.

Interview questions were created based on the results of feedback, and a large majority of the responses were related to human resources development and procurement. Rather than developing human resources from scratch, there is a tendency to acquire talented employees through head-hunting. However, there are costs involved and it is not necessary to employ large numbers of people, so it is considered important to find a small number of highly talented prospects.

Vietnamese people also tend to dislike doing dirty work and strongly prefer to be in charge, which means that talented people often start their own business. Furthermore, it costs less to use people rather than investing in machinery and equipment, and can sometimes lead to improvements in quality. Actually, companies such as Toyota Vietnam are doing similar things.

\subsection{Identifying the Requisite Elements for NVPM}

The authors took the information obtained from company surveys conducted in Japan and Vietnam and categorized the information according to 4ME (Man, Machine, Material, Method, and Environment).

Next, they conducted text mining using the categorized key words. The use of text mining enabled the authors to investigate the relationship between the production models in Japan and Vietnam, and then summarize the characteristics common to the Japanese model and the Vietnamese model, as well as the distinctive characteristics of each model in order to objectify the various elements.

The results of the text mining are summarized in Fig.5 and 6. The distinctive characteristics of the Japanese model and the Vietnamese model were identified, and then the characteristics common to both models were identified.

First, we will explain the elements categorized by the text mining, considering the four items organized by using the sticky notes from the perspective of 4ME. The obtained data was organized as shown in Fig.5 and 6. Arrows are used to show the associations between words, and the arrows are concentrated around words that have strong associations.

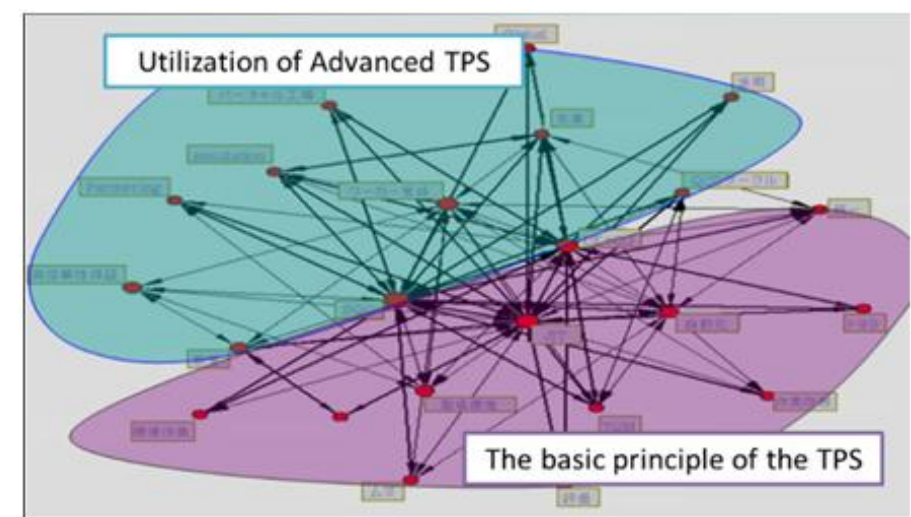

Fig.5: Text Mining of TPS and Advanced TPS

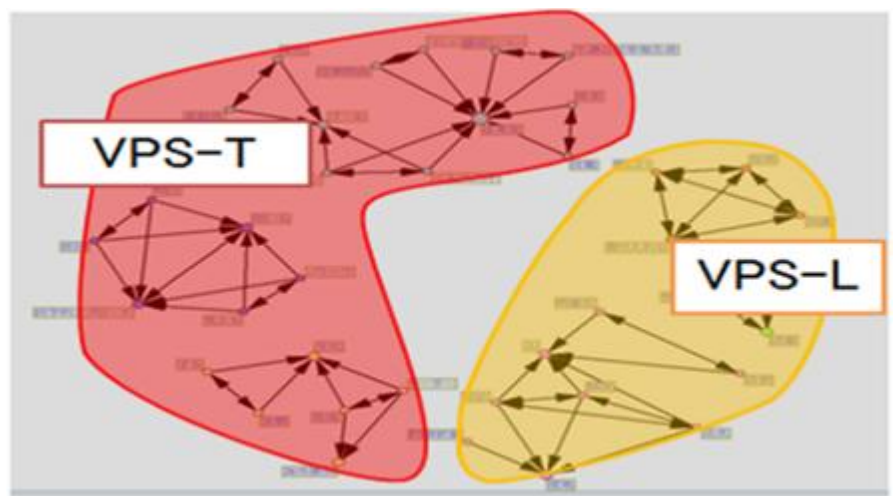

Fig.6: Text Mining of VPS-T and VPS-L 


\subsection{Constructing NVPM}

The use of text mining enabled TPS, Advanced TPS, VPS-T, and VPS-L to be identified as the relevant elements. This model utilizes TPS and Advanced TPS, and encompasses VPS-T and VPS-L. The left side of the model is comprised of TPS and Advanced TPS while, similarly, the right side is comprised of VPS-T and VPSL.

As far as the authors are aware, there has been no other research on efficient production systems in Vietnam up to now. Thus, utilizing their production-related findings from research in China and other parts of Asia, including Japan, the authors aim to develop local production to ensure survival amidst global competition. As Vietnam has not yet become an advanced country, the authors anticipate the need for production capabilities equivalent to those of advanced countries.

In proposing this model, the authors anticipate improvements in productivity to be achieved by creating links with all production systems, possessing advanced technological capabilities, and implementing thorough kaizen of local production in Vietnam. A NVPM model proposed by the consumers is as shown in Fig.7.

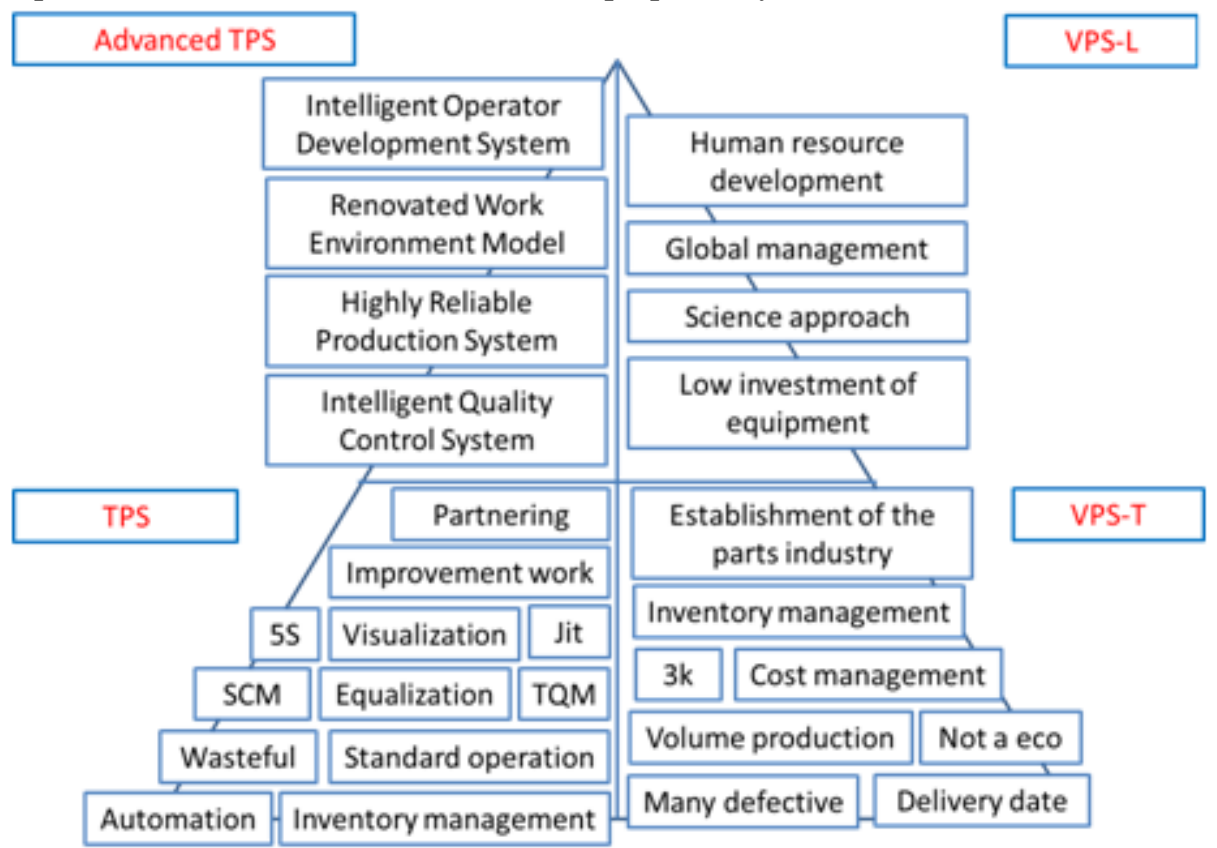

Fig.7: Outline of a New Vietnam Production Model, NVPM

In order to evaluate the effectiveness of the proposed NVPM, the authors conducted questionnaire surveys targeting company employees that have had the experience of being based in Vietnam, and collated the results. A 7-level evaluation system was used for the questionnaires, and the questions were devised based on 18 items derived from feedback during the field surveys.

The questionnaire mainly covered elements considered necessary to develop workers at Vietnamese plants into highly skilled human resources. Of the 41 people asked to participate in the questionnaire survey, responses were obtained from 36 people. The contents of the questionnaire are enumerated as follows.

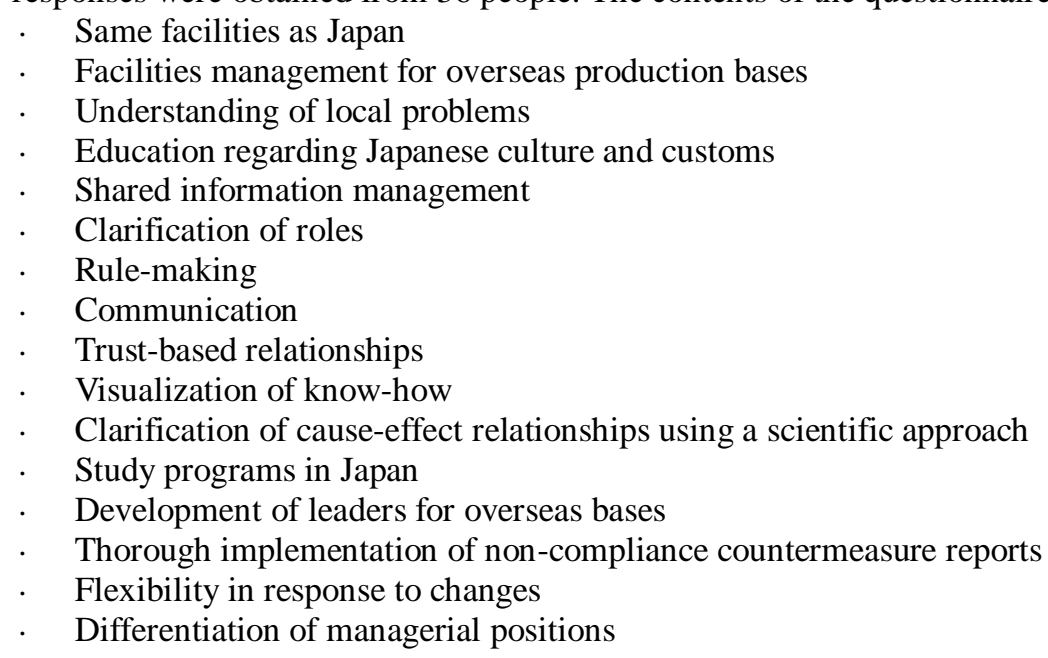


- Human resources development and training system for local employees

Development of equipment suitable for local people

Guidance that incorporates new knowledge

Management goals and visions for employees

The items of questionnaire content were extracted from raw data obtained during field surveys and interviews conducted in Vietnam. Most of these items relate to people. This is probably due to differences in culture and regional characteristics.

Multiple regression analysis was conducted using the collated results to analyze the degree of importance. The results of the multiple regression analysis are as shown in Table 1.

Table 1: The results of multiple regression analysis

\begin{tabular}{|l|c|}
\hline \multicolumn{1}{|c|}{ Variable name } & $\begin{array}{c}\text { Partial regression } \\
\text { coefficient }\end{array}$ \\
\hline Guidance that incorporates new knowledge & 0.914 \\
\hline $\begin{array}{l}\text { Human resources development and training } \\
\text { system for local employees }\end{array}$ & 0.523 \\
\hline Flexibility in response to changes & 0.493 \\
\hline Understanding of local problems & 0.364 \\
\hline Development of leaders for overseas bases & 0.344 \\
\hline Communication & 0.157 \\
\hline Rule-making & 0.125 \\
\hline
\end{tabular}

Based on the relative size of the partial regression coefficients shown in Table 1, the authors identified "Guidance that incorporates new knowledge", "Human resources development and training system for local employees", "Flexibility in response to changes", and "Development of leaders for overseas bases". While actually working at a local site, the authors were told that "Vietnamese workers are not particularly sensitive to new things in the world around them", which reaffirmed the importance of gaining new knowledge for Vietnamese people.

\section{Verification}

In order to verify the effectiveness of the model, the authors conducted the questionnaire survey. The survey targeted workers either with the experience of working, or currently working, at overseas bases.

The aim of this questionnaire survey was to receive raw feedback (free opinions) concerning the proposed model in order to lend credibility to the verification (evaluation). The main opinions received are listed below.

- If a model existed that was suitable for both advanced countries and developing countries, it would be applied a lot more.

- This is the first time I've ever considered the matter objectively, so it's very interesting.

- The practicality would be much greater if it was possible to search related cases in real-time.

Based on the above opinions, it is possible to ascertain that the model will be both necessary and effective at actual production sites. The authors consider that more extensive application of the model will be necessary, in order to further verify the effectiveness and identify more issues.

\section{Conclusion}

Through this research, the authors have constructed a "New Vietnam Production Model, NVPM" with the aim of contributing to the development of the manufacturing industry in Vietnam. The ultimate objective of Japanese companies is to enhance the locally-based production technology without placing a burden on Japan, in order to effectively and efficiently maintain a level of quality that is equivalent to or above that in Japan.

In the future, the authors intend to apply the proposed model to the Vietnamese manufacturing industry and verify its effectiveness. 


\section{References}

[1]. Amasaka,K, New JIT, A New Management Technology Principle at Toyota, International Journal of Production Economic, $80,2002,135-144$.

[2]. Amasaka,K,New Japan Model : Science TQM-Theory and Practice of Strategic Quality Management, Maruzen (in Japanese,2007).

[3]. Amasaka,K, Strategic QCD Studies with Affiliated and Non-affiliated Suppliers utilizing New JIT, Encyclopedia of Networked and Virtual Organizations,2008,1516-1527.

[4]. Amasaka,K, The Foundation for Advancing the Toyota Production System Utilizing NEW JIT, Journal of Advanced Manufacturing Systems, 8,2009,5-26.

[5]. Amasaka,K,(Ed.)Science TQM, New Quality Management Principle: The Quality ManagementStrategy of Toyota, (Bentham Science Publishers.2012)

[6]. Amasaka,K.and Sakai,H.V-MICS, Advanced TPS for Strategic Production Administration: Innovative Maintenance Combining DB and CG, J. AdvancedManufacturing Systems,4, 2005, 5-20.

[7]. Amasaka,K.and Sakai,H.TPS-LAS Model Using Process Layout CAE System at Toyota, Advanced TPS: Key to Global Production Strategy New JIT, J. Advanced Manufacturing Systems, 5, 2006a, 1-14.

[8]. Amasaka,K.and Sakai,H.Strategic HI-POS, Intelligence Production Operating System - Applying Advanced TPS to Toyota's Global Production Strategy, WSEAS Transactions on Advances in Engineering Education, Issue 3, 2006b, 223-230.

[9]. Amasaka,K.and Sakai,H.TPS-QAS, New Production Quality Management Model: Key to New JIT, Toyota's Global Production Strategy, Int. J. Manufacturing Technology and Management, 18, 2009, 409-426.

[10]. Amasaka,K.and Sakai,H.Evolution of TPS Fundamentals Utilizing NEW JIT Strategy: Proposal and Validity of Advanced TPS at Toyota, Journal of Advanced Manufacturing Systems.9.2010,85-99

[11]. Ebioka,K. Yamaji.M, Sakai.H, and Amasaka.K, A New Global PartneringProduction Model "NGP-PM" utilizing Advanced TPS, Journal of Business \& Economics Research,5, 2007,1-8.

[12]. J,P, Womack, D.T.Jones, and D.Roos, The Machine that Change the World The Story of Lean Production,(Rawson/Harper Perennial.1991)

[13]. J,P, Womack, and D.T.Jones, From lean production to the lean enterprise. (Harvard Business Review, 1994,93-103.)

[14]. Ohno.T, Toyota production system.(Diamond-sha and Toyota Motor Corp,1987).

[15]. Yeap,Y,S. Murat.M.S, Amasaka.K, Proposal of New Turkish ProductionSystem NTPS, Integration and Evolution of Japaneseand Turkish Production System, Journal of Business Case Study, 6,2010, 69-76. 